\title{
Relato de caso: Pneumonia de Hipersensibilidade
}

Camila Ribas Stefanello1; Isabela Borella da Silva1; Patrícia Tirelli Lena1; Paula Aguiar Grandi'; Patrícia Formigheri Feldens²; Fabio Fernandes Cardoso ${ }^{3}$

\section{Resumo}

Introdução: A Pneumonia por hipersensibilidade - ou alveolite alérgica extrínseca -, é uma síndrome cuja inflamação no parênquima pulmonar é causada pela inalação de um antígeno orgânico desencadeador ou de uma substância de baixo peso molecular em pessoas previamente sensibilizadas. ${ }^{1}$ As suas características clínicas e radiológicas são consideradas inespecíficas, sobrepondo-se com outras formas de doença pulmonar intersticial difusa. ${ }^{2} \mathrm{O}$ relato de caso é de um paciente admitido em hospital do interior do Rio Grande do Sul com suspeita de pneumonia comunitária grave, porém apesar de todo o suporte terapêutico, inclusive com antibióticos de amplo espectro, evoluiu com piora clínica sustentada até insuficiência respiratória aguda, com necessidade de suporte ventilatório mecânico em Unidade de Terapia Intensiva. Durante sua estadia nunca foi isolado germe e culturas. Aventando hipótese diagnóstica de pneumonia de hipersensibilidade após relado de familiares sobre exposição a diversos fatores alérgenos. A pneumonia de hipersensibilidade foi confirmada por Biopsia pulmonar.

Método: O presente relato foi elaborado de acordo com o prontuário hospitalar do paciente, diante autorização de familiar responsável, e com revisão de literatura.

Resultados: Com o resultado da biopsia pulmonar se iniciou tratamento com corticoide havendo melhora importante, porém sequelas como fibrose pulmonar permaneceram.

Conclusões: $O$ reconhecimento e o diagnóstico de pneumonia de hipersensibilidade crônica é considerado um desafio, devido a dificuldade em identificar uma relação temporal entre os sintomas e uma exposição ambiental específica. ${ }^{2}$ Em muitos casos, como no presente, o diagnóstico de exclusão. Corticoesteróides se mostram resolutivos para o tratamento dos sinais, mas, dependendo da evolução da doença até a confirmação diagnóstica, podem 
haver sinais crônicos pela formação de fibrose no parenquima pulmonar que deve ser acompanhados para melhor prognóstico.

Palavras Chave: Pneumonia de hipersensibilidade, Fibrose pulmonar, Diagnóstico de exclusão.

\section{Introdução}

A Pneumonia por hipersensibilidade - ou alveolite alérgica extrínseca -, é uma síndrome cuja inflamação no parênquima pulmonar é causada pela inalação de um antígeno orgânico desencadeador ou de uma substância de baixo peso molecular em pessoas previamente sensibilizadas.(1) As suas características clínicas e radiológicas são consideradas inespecíficas, sobrepondo-se com outras formas de doença pulmonar intersticial difusa.(2) $O$ relato de caso é de um paciente admitido em hospital do interior do Rio Grande do Sul com suspeita de pneumonia comunitária grave, porém apesar de todo o suporte terapêutico, inclusive com antibióticos de amplo espectro, evoluiu com piora clínica sustentada até insuficiência respiratória aguda, com necessidade de suporte ventilatório mecânico em Unidade de Terapia Intensiva. Durante sua estadia nunca foi isolado germe e culturas. Aventando hipótese diagnóstica de pneumonia de hipersensibilidade após relado de familiares sobre exposição a diversos fatores alérgenos. A pneumonia de hipersensibilidade foi confirmada por Biopsia pulmonar (BX).

\section{Objetivo}

Relatar e discutir um caso de pneumonia de hipersensibilidade, com manifestações iniciais de pneumonia comunitária.

\section{Relato de caso}

Paciente masculino, 48 anos, tabagista, previamente hígido, procurou atendimento médico por apresentar febre alta e dor de garganta. Familiares referiram que a única alteração de hábitos foi após colher flores e fixar móveis em sua casa. Foi admitido no hospital do seu município com suspeita de pneumonia comunitária. Fez grande suporte terapêutico com uso de antibióticos de amplo espectro, porém evoluiu com piora clínica.

Devido a evolução até insuficiência respiratória, o paciente foi transferido para hospital referência na região, onde foi admitido para a Unidade de Terapia Intensiva (UTI) necessitando suporte ventilatório mecânico. 
Prosseguiu-se investigação do quadro com realização de exames de cultura, os quais não apresentaram identificação de germe.

O quadro do paciente evoluiu, levantando suspeita e confirmando diagnóstico de síndrome da angustia respiratória aguda (SARA) com formação de fibrose pulmonar, com pouca melhora.

Continuou-se a investigação do paciente e aventou-se hipótese de pneumonia de hipersensibilidade, a qual foi confirmada após BX pulmonar. Após confirmação, o paciente vem fazendo uso de corticoides sistêmicos, apresentando leves melhoras, e ainda necessitando de ventilação mecânica.

\section{Discussão}

Pneumonia por hipersensibilidade é uma síndrome complexa, desencadeada devido a inalação de antígenos. Suas formas de apresentação são aguda, subaguda e crônica, isso irá depender da quantidade, do tempo de exposição, da natureza do antígeno e da resposta imune do paciente. (3) A forma aguda caracteriza-se pela apresentação dos sintomas entre quatro e oito horas após a exposição. A forma subaguda é caracterizada por dispneia aos esforços, fadiga, tosse, emagrecimento e na maioria dos casos, associa-se a inalantes domiciliares. Nesse caso, o paciente apresentou um início subagudo e agora é considerado crônico. (4)

A PH é uma das poucas patologias que pacientes tabagistas têm menor predisposição ao desenvolvimento da doença $(1,4)$. Fato interessante, visto que o paciente relatado era tabagista, de carga tabágica de 8,75 anos/maços.

A PH é de difícil diagnostico, porém é de extrema importância que esse seja feito o mais precocemente possível. Além disso, seja feita a coleta da história do paciente - exposição -, os dados clínicos e os achados dos exames de imagens. Contudo, o método ouro para diagnostico é a biópsia pulmonar. (5)

O caso relatado comprova a necessidade de uma investigação clínica mais acentuada, para que o paciente seja adequadamente tratado. Além disso, comprova que o histórico do paciente pode predizer a história da doença atual, visto que a hipótese de pneumonia de hipersensibilidade foi levantada após os relatos de o paciente ter, possivelmente, inalado antígenos. 
${ }^{1}$ Graduando do curso de Medicina do Centro Universitário Univates, Lajeado (RS).

2 Médica nefrologista do Hospital Bruno Born, Lajeado (RS), do Hospital Estrela, Estrela (RS) e professora adjunta do curso de Medicina do Centro Universitário Univates, Lajeado (RS).

${ }^{3}$ Médico intensivista e coordenador da UTI adulto do Hospital Bruno Born, Lajeado (RS).

\section{Referências:}

1 - Lacasse Y, Selman M, Costabel U, Dalphin JC, Ando M, Morell F et al. Clinical diagnosis of hypersensitivity pneumonitis. Am J Respir Crit Care Med. 2003;168(8):952- 8.

2- Myers J. Hypersensitivity pneumonia: the role of lung biopsy in diagnosis and management. Modern Pathology (2012) 25, S58-S67; doi:10.1038/modpathol.2011.152

3- Fan LL. Hypersensitivity Pneumonitis in Children. Curr Opin Pediatr 2002;4:323-6.

4-Schuyler M, Gott K, Cherne A. Mediators of hypersensitivity pneumonitis. J Lab Clin Med 2000;136:29-38.

5- Matar LD, McAdams HP, Sporn TA. Hypersensitivity pneumonitis. Am J Roentgenol 2000;174:1061-6. 